\title{
Inhalt.
}

Vorwort . . . . . . . . . . . . . . . . . $\mathrm{m}$

I. Allgemeiner Teil.

Erstes Kapitel. Die Geschichte der Sehnenüberpflanzung . . 1 Zweites Kapitel. Die Indikationen der Sehnenüberpflanzung . 12 Drittes Kapitel. Die Technik . . . . . . . . . . . . 26 Viertes Kapitel. Die Resultate . . . . . . . . . . . . 77

\section{Spezieller Teil.}

Einleitung . . . . . . . . . . . . . . . . . . . . . . 95

Erstes Kapitel. Die Sehnenüberpflanzung bei peripherer Lähmung 96

A. Untere Extremität . . . . . . . . . . . . . . . 97

1. Lähmung durch Sehnenverlust . . . . . . . . . . 97

2. Lähmung der peripheren Nervenstämme . . . . . . 100

a) Kontinuitätstrennung der Nerven . . . . . . . . 100

b) Degeneration der Nerven durch Überdehnung . . . 102

c) Degeneration der Nerven durch Quetschung . . . . 103

d) Neuritische Entartung der Nerven . . . . . . . 105

B. Obere Extremität . . . . . . . . . . . . . . . 107

1. Lähmung durch Sehnenverlust . . . . . . . . . 107

a) Extensoren der Finger und des Daumens . . . . . 107

b) Flexoren des Daumens und der Finger. . . . . . 111

2. Traumatische Lähmung der Armnervenstämme . . . . 115

Zweites Kapitel. Die Sehnenüberpflanzung bei der spinalen

Kinderlähmung . . . . . . . . . . . . . . . . . . 121

a) Der spinal gelähmte Unterschenkel. Einleitung, Technik, Operationspläne . . . . . . . . . . . . . . . 122

1. Der paralytische Spitzfuß . . . . . . . . . . 143

2. Der paralytische KlumpfuB . . . . . . . . . . 145

3. Der paralytische PlattfuB . . . . . . . . . . 152 
4. Das schlotternde Sprunggelenk . . . . . . . . . . $\quad \begin{array}{r}\text { Seite } \\ 155\end{array}$

5. Der paralytische HackenfuB . . . . . . . . . . 157

b) Der spinal gelähmte Oberschenkel . . . . . . . . 171

c) Spinale Lähmung an Hand und Vorderarm . . . . . 187

d) Spinale Lähmung des Oberarmes . . . . . . . . . 195

Drittes Kapitel. Die Sehnenüberpflanzungbei spastischerLähmung 197

A. Die spastische Hemiplegie . . . . . . . . . . . . 197

1. Die cerebrale Kinderlähmung . . . . . . . . . . 197

a) Überpflanzungen am Unterschenkel . : . . . . . 198

b) Überpflanzung am Oberschenkel . . . . . . . . . . 201

c) Überpflanzung am Vorderarm . . . . . . . . . . . 202

d) Überpflanzung an der Hand . . . . . . . . . . . . 209

2. Die apoplektische Hemiplegie . . . . . . . . . . 210

B. Die spastische Diplegie . . . . . . . . . . . . . 213

Viertes Kapitel. Die Sehnenüberpflanzung bei arthrogener Kniekontraktur . . . . . . . . . . . . . . . . . . . 225

Fünftes Kapitel. Die Sehnenüberpflanzung beim angeborenen

KlumpfuB . . . . . . . . . . . . . . . . , . . 230

Sechstes Kapitel. Varia . . . . . . . . . . . . . . 234

Litteraturverzeichnis . . . . . . . . . . . . . . 238 
